\title{
Coral mutualists enhance fish abundance and diversity through a morphology-mediated facilitation cascade
}

\author{
Gerick S. Bergsma* \\ Department of Ecology, Evolution, and Marine Biology, University of California, Santa Barbara, California 93106, USA \\ Present address: Division of Science and Environmental Policy, California State University Monterey Bay, Seaside, \\ California 93955, USA
}

\begin{abstract}
Taxa that alter the morphology of foundation species have the potential to indirectly affect organisms that use the foundation species for habitat. On tropical reefs, coral morphology can be altered by epibiotic symbionts, potentially affecting fish populations that use coral as refuge. In the lagoons of Moorea, French Polynesia, mutualistic gammarid amphipods and chaetopterid polychaetes induce the growth of branch-like 'fingers' on corals of the genus Montipora. I tested whether these fingers create habitat for reef fish, and found that juvenile and adult fish sheltered and larvae settled among fingers on both natural and experimental reefs. While the habitat structure induced by the mutualists appears to be of lower quality than that provided by branching corals such as Pocillopora sp., the presence of these structures in areas of the reef devoid of branching corals likely means that mutualist-induced structures increase the abundance and diversity of reef fish at the landscape scale.
\end{abstract}

KEY WORDS: Trait-mediated indirect interaction - Facilitation cascade $\cdot$ Habitat complexity · Mutualism · Coral morphology · Fish recruitment · Montipora · Gammarid amphipod

\section{INTRODUCTION}

Species that create biogenic structure or alter the physical environment can facilitate other organisms in the environment by creating habitat (Bertness \& Callaway 1994, Jones et al. 1994, Stachowicz 2001). Such foundation species or ecosystem engineers give rise to important indirect interactions (Wootton 1994, Menge 1995), including facilitation cascades that can alter abundance, diversity, and productivity of organisms within their community (Altieri et al. 2007, Thomsen et al. 2010).

The effects of habitat-forming species arise from the physical structure they provide, and the degree of facilitation can relate to the habitat complexity that they generate (Jones et al. 1997, Bruno \& Bertness 2001). Community structure is therefore directly linked to the behavioral and physical traits of individuals of these species; changes in the properties of their traits can influence the strength of the positive interactions they form (Gribben et al. 2009, Irving \& Bertness 2009). This creates potential for trait-mediated indirect interactions to structure communities; for example, Gribben et al. (2009) showed that behavior-mediated interactions among habitat-forming plants and mussels controlled species richness in a soft-bottom marine community. Because many important habitat-forming species are morphologically plastic (e.g. Callaway et al. 2003, Todd 2008), morphology-mediated indirect interactions are also likely to be ecologically important, but the effects of induced morphological traits on community processes are largely unexplored. 
I sought to demonstrate how the morphological response of a foundation species to an epibiotic mutualist affects species diversity and abundance. On tropical reefs, coral growth and morphology drive the local diversity and abundance of reef-associated species (Kohn 1983, Vytopil \& Willis 2001, Holbrook et al. 2002). Many reef fish shelter within corals at various life stages. For example, many newly settling larvae, which are particularly vulnerable to predation, settle to corals with high structural complexity (Ohman et al. 1998, Nakamura et al. 2009). Reef fish demographics are therefore closely coupled to coral habitat; fish recruitment and abundance are limited by habitat availability (Holbrook et al. 2000, 2008, Schmitt \& Holbrook 2000), and increase with habitat complexity (Gladfelter \& Gladfelter 1978, Holbrook \& Schmitt 2002). Factors increasing the availability and complexity of coral structure may enhance reef fish populations.

Symbiotic organisms can change growth patterns and alter the physical structure of corals (Abelson et al. 1991, Liu \& Hsieh 2000, Wielgus et al. 2002). Mutualistic gammarid amphipods and chaetopterid polychaetes, for example, induce the growth of long, finger-like coral projections ('fingers') on colonies of Montipora in Moorea, French Polynesia (Bergsma 2009; Fig. 1). The presence of this induced biogenic structure enhances coral growth and survival (Bergsma \& Martinez 2011). The fingers also add significant 3dimensional structure to the reef; Bergsma (2009) estimated that $\sim 2400 \mathrm{~cm}^{3}$ of space is created between fingers for each $1000 \mathrm{~cm}^{2}$ of coral basal area on fingered colonies. If fingers provide shelter to fish, then the coral mutualists may indirectly increase reef fish populations by augmenting refuge space and increasing habitat area across the lagoons. In this study, I tested whether fish utilize fingered Montipora as refuge from predation and as settlement habitat, and sought to understand how the presence of coral symbionts might impact reef fish abundance and diversity across lagoons.

\section{MATERIALS AND METHODS}

\section{Collection and study sites}

I conducted laboratory experiments at the UC Berkeley Gump South Pacific Research Station and field activities along the north shore of Moorea, French Polynesia. A barrier reef encloses lagoons ranging 0.8 to $1.3 \mathrm{~km}$ in width that comprise reef flats, channels, and fringe reefs (for detailed descriptions of the lagoons see Galzin \& Pointier 1985). Reef flats ranged from 2 to $6 \mathrm{~m}$ in depth and consisted of areas with continuous coral cover, patch reefs interspersed with coral rubble and sand, and large sand flats.
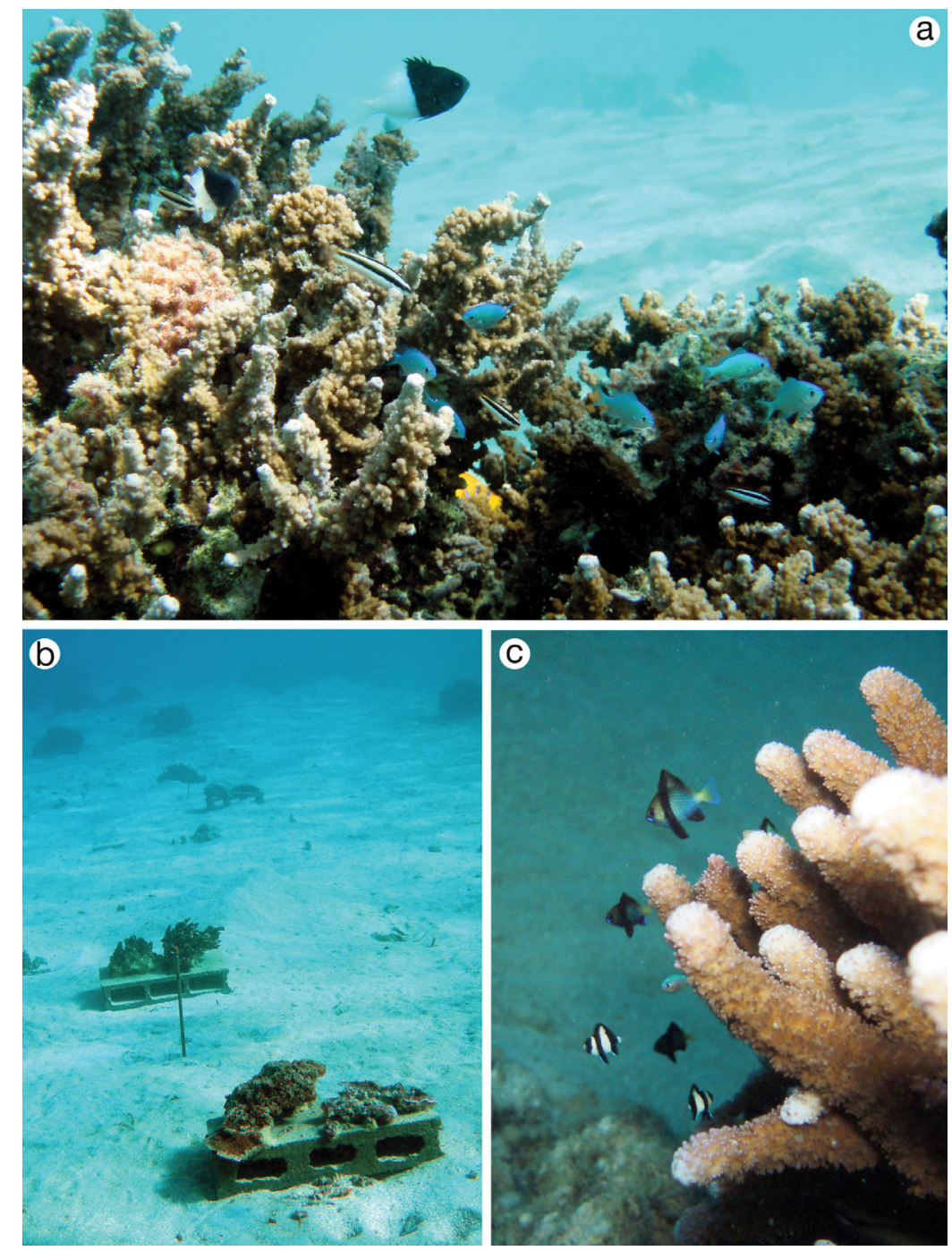

Fig. 1. (a) Juvenile reef fish sheltering among Montipora fingers, (b) experimental reefs placed within a sand flat, and (c) newly settled damselfish on an experimental reef with fingers 
Surveys documenting the use of fingers by reef fish were conducted in continuous reef, patch reef, and sand flat habitats in 6 of the lagoons: Ahuru $\left(17^{\circ} 29^{\prime} 55^{\prime \prime} \mathrm{S}, 149^{\circ} 55^{\prime} 10^{\prime \prime} \mathrm{W}\right)$, Tiahura $\left(17^{\circ} 29^{\prime} 21^{\prime \prime} \mathrm{S}\right.$, $\left.149^{\circ} 54^{\prime} 0^{\prime \prime} \mathrm{W}\right)$, Vaipahu (17²8' $\left.49^{\prime \prime} \mathrm{S}, 149^{\circ} 50^{\prime} 12^{\prime \prime} \mathrm{W}\right)$, Maharepa $\left(17^{\circ} 28^{\prime} 57^{\prime \prime} \mathrm{S}, 149^{\circ} 49^{\prime} 42^{\prime \prime} \mathrm{W}\right)$, Teharoa $\left(17^{\circ} 28^{\prime} 27^{\prime \prime} \mathrm{S}, 149^{\circ} 47^{\prime} 12^{\prime \prime} \mathrm{W}\right)$, and Temae $\left(17^{\circ} 29^{\prime}\right.$ $\left.59^{\prime \prime} \mathrm{S}, 149^{\circ} 45^{\prime} 27^{\prime \prime} \mathrm{W}\right)$. Montipora colonies used for artificial reefs in the fish settlement experiment were collected in the Vaipahu lagoon and deployed at the eastern edge of the lagoon, near the opening of Cook's Bay $\left(17^{\circ} 28^{\prime} 55^{\prime \prime} \mathrm{S}, 1^{\circ} 9^{\circ} 49^{\prime} 31^{\prime \prime} \mathrm{W}\right)$. Coral colonies and juvenile bluegreen chromis Chromis viridis were collected for the refuge quality experiment from the Vaipahu and Teharoa lagoons, and spotfin squirrelfish Neoniphon sammara were collected from the fringe reef adjacent to the research station $\left(17^{\circ} 29^{\prime} 27^{\prime \prime} \mathrm{S}, 149^{\circ} 49^{\prime} 34^{\prime \prime} \mathrm{W}\right)$.

\section{Study species}

Tube-dwelling amphipods (Gammaropsis sp.) and polychaetes (Spiochaetopterus sp.) induce the formation of branch-like fingers on Montipora spp. corals (Bergsma 2009). Montipora is typically encrusting or plating, but the symbionts alter the colonies morphology by forming tubes that are encrusted by the coral. Colonies with fingers resemble branching corals in morphology, and are ubiquitous throughout Moorea's northern lagoons where Montipora is one of the dominant coral genera (Bergsma 2009).

Species of the genus Montipora are difficult to distinguish and have poorly resolved taxonomy, so all corals were treated at the generic level (see Bergsma 2009 for a list of Montipora species that may associate with finger-forming symbionts). However, I attempted to use a single morphospecies (possibly $M$. aequituberculata) for experiments. The fingers formed by the amphipods and polychaete worms are similar in shape and size and may cooccur on the same colonies, so I did not distinguish among symbiont species when selecting corals for this study.

At least 37 fishes belonging to 18 families were observed sheltering on Montipora (Appendix 1). Of these, the Pomacentridae were most abundant and speciose, followed by the Apogonidae, Labridae, Holocentridae, Acanthuridae, and Chaetodontidae. Most fish were resident juveniles that sheltered among the fingers. The pomacentrids, apogonids, and holocentrids likely use the finger structures throughout their lives, and were commonly observed occupying the coral as both juveniles and adults. The labrids, acanthurids, and chaetodontids, however, were mostly observed using fingers as juveniles. They do not appear to reside in Montipora as adults, although transient adults sometimes took refuge among fingers when divers approached. The few fish encountered on Montipora without fingers were mostly pairs of adult pomacentrids that appeared to be defending ledges formed by coral plates presumably used as nesting sites.

Species that were difficult to distinguish were only identified to family. The gobies (Gobiidae) proved especially difficult to quantify because of their cryptic habits and the difficulty in separating those that were residing on the substratum beneath ledges formed by fingers from those that actually used fingers for shelter, and so were excluded from analysis. Fish that use large holes and crevices within or under corals (e.g. Balistidae, Muraenidae, Serranidae) were only included when the fingers composed a major part of the structure in which they were sheltering.

\section{Fish settlement on experimental reefs}

I tested the effects of fingers on fish settlement and habitation using a field experiment. I selected Montipora colonies from the lagoon and categorized their morphology as 'fingered' for encrusting colonies covered with mutualist-induced structures $>2 \mathrm{~cm}$ in length, or 'flat' for encrusting or plating colonies with no fingers. Corals were then brought to the study site, a large sandy slope with low coral cover ranging 1 to $6 \mathrm{~m}$ in depth.

At the study site, I attached corals to cement blocks using marine epoxy to form small artificial reefs ranging from 600 to $800 \mathrm{~cm}^{2}$ in coral basal area. Reefs consisted of either fingered or flat colonies. Fingered reefs were paired with flat reefs of similar coral basal area and distributed in pairs spaced $6 \mathrm{~m}$ apart across the slope at $3 \mathrm{~m}$ depth (e.g. Fig. 1). Reefs within each pair were spaced $2 \mathrm{~m}$ apart and at least $4 \mathrm{~m}$ from natural corals, isolating them so that divers could unambiguously determine which fish associated with each reef. In total, 34 reefs (17 pairs) were used in the study.

At the beginning of the experiment, divers cleared the reefs of fish using hand nets. The reefs were first surveyed 2 wk after clearing, and then monitored every 2 to $3 \mathrm{~d}$ for $2 \mathrm{wk}$. For each survey, all fish residing within or hovering above the experimental reefs 
were identified, categorized as new settlers, juveniles, or adults, and counted.

I tested for differences in the abundance and species richness of juvenile and adult fish between reefs with and without fingers using repeated measures analyses of variance (ANOVAs), with modeling time and morphology as fixed effects and reef pair as a random effect. Near the end of the experiment, a pulse of larval fish settled on the reefs, allowing a test of the effects of the morphology on fish settlement. Due to the small number of newly settled fish and high variance among reefs, I used a Fisher's sign test to detect differences among reefs in the abundance and species richness of settlers.

\section{Patterns of fish occurrence in Montipora}

I surveyed for fish using fingers as refuge at 18 sites in continuous reef, patch reef, and sand flat habitats throughout the northern lagoons. I selected Montipora colonies with fingers (defined as colonies with at least 2 mutualist-induced structures $>2 \mathrm{~cm}$ in length) using haphazardly placed band transects. In continuous and patch reef habitats, I surveyed all fingered Montipora colonies found within $25 \mathrm{~m}$ long and $2 \mathrm{~m}$ wide band transects. To survey similar numbers of corals in sand patch habitats, I used $25 \mathrm{~m}$ long and $10 \mathrm{~m}$ wide transects. I measured the diameter of each colony along its major and minor axis, and the distance to the nearest branching coral (including Acropora spp., Pocillopora spp., and Porites rus, but excluding other Montipora with fingers). All fish found hiding among the fingers were identified and counted.

Colony diameter measurements were used to calculate the individual density and species density of fish inhabiting each coral by estimating the basal area of colonies as an ellipse. A 1-way ANOVA, with a post hoc Tukey test, tested for differences in density of fish and of species among habitats. To further explore fish-habitat relationships in sand flats, I performed a multiple regression to test the effects of colony area and distance from the nearest branching coral on fish abundance.

\section{Quality of coral structure as refuge}

I conducted laboratory experiments to test for differences among corals in refuge quality for juvenile fish. Small colonies of Pocillopora verrucosa and fingered and flat Montipora sp., ranging in size from 12 to $20 \mathrm{~cm}$ in maximum diameter, were collected from the lagoon and placed individually in $60 \times 30 \times 30 \mathrm{~cm}$ acrylic aquaria maintained with continuously flowing sea water in a covered outdoor laboratory. For each trial, 10 randomly selected juvenile bluegreen chromis Chromis viridis were introduced into each aquarium and acclimated for $\sim 15$ min to allow the fish to shelter within the coral. Individuals of the spotfin squirrelfish Neoniphon sammara, a common piscivore, were then placed in each tank and left for $24 \mathrm{~h}$. At the end of the trial, the coral and fish were removed from the tank, and the number of surviving chromis was counted.

New chromis were used for each trial. I employed a repeated measures design where each individual predator was used in trials with all 3 coral types. In total, 18 squirrelfish were used, and to refine estimates for individual squirrelfish, I used each predator in 4 trials with each type of coral (for a total of 12 measures per predator). Trials were conducted consecutively for each predator; following each trial, predators were immediately placed into a new trial. The predators continued to eat through all trials, and there did not appear to be any trends in the number of prey consumed over time for individual predators for a given coral type. The order in which different corals were paired with each predator was randomized to account for behavioral conditioning of predators to certain coral types. I tested for differences in the mean number of fish remaining among coral types using a mixed-effect linear model. I included squirrelfish as a random effect in the model to account for repeated measures of each individual, and tested for pairwise differences between coral types using a post hoc Tukey test on the estimated least squares means derived from the model.

\section{Quantification of lagoon habitats}

Preliminary observations indicated differences in the use of Montipora by fish among different lagoon habitats and that the lagoon-scale effects of the finger structures might be tied to the spatial distribution of habitats within the lagoon. Therefore, I determined the spatial arrangement of habitats and the percent of the northern lagoons that were sand flats using satellite imagery from Google Earth ${ }^{\mathrm{TM}}$. The images show topographical features of the shallow benthos, and were used to differentiate sand flats from patch and contiguous reef habitats. I imported images of lagoons into ImageJ image analysis software (Rasband 2005), and used the 
pixel area of polygons encompassing entire lagoons and areas identified as sand flats to calculate the percent of each lagoon composed of sand flats. I defined lagoons as reef flats and backreef areas between reef passes, extending from the reef crest to either shore or deep water (i.e. the benthos was not visible in the satellite images); I excluded bays, deep-water channels, and fringe reefs that were separated from the reef flat by deep-water channels from the estimates.

\section{RESULTS}

\section{Fish settlement on experimental reefs}

The field experiments showed that morphology had a significant effect on the number of individual fish present $\left(F_{1,16}=33.21, \mathrm{p}<0.0001\right)$, with fingered reefs harboring 4 to 6 times more fish during the experiment (Fig. 2a). The corals did not saturate with fish over the course of the experi-
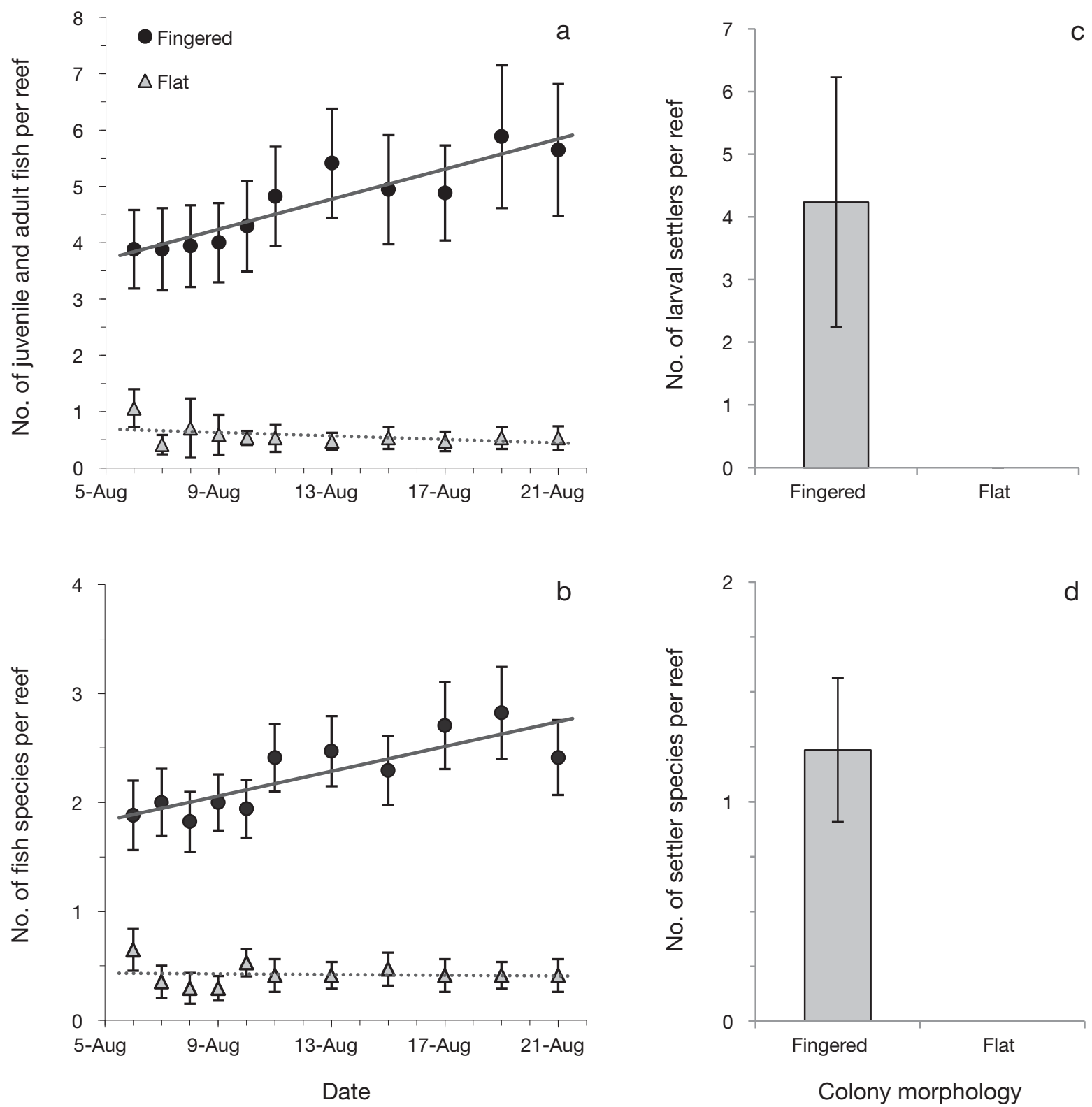

Fig. 2. (a) Number of juvenile and adult fish and (b) number of fish species inhabiting outplanted reefs with either fingered or flat colonies of Montipora during the last $2 \mathrm{wk}$ of the 4 experimental weeks. (c) Number of newly settled fish and (d) number of species of new settlers inhabiting outplanted reefs with either fingered or flat colonies of Montipora following a pulse of settlement to the lagoon. All means $\pm \mathrm{SE}$ 
ment, and a non-crossing interaction between fish abundance and time arose from fingered reefs accruing fish at a greater rate than flat reefs (Time $\times$ Morphology: $\left.F_{1,356}=18.08, \mathrm{p}<0.0001\right)$. Reef morphology similarly had a significant effect on species richness $\left(F_{1,16}=46.71, \mathrm{p}<0.0001\right)$, with fingered reefs having 2 to 3 times more species than flat reefs (Fig. 2b). Again, fingered reefs gained species at a greater rate than flat reefs (Time $\times$ Morphology: $F_{1,356}=21.00, \mathrm{p}<0.0001$ ) .

Reefs with fingers also had a significantly greater number (Fisher binary test: $\mathrm{B}_{\mathrm{F} n=11}=11, \mathrm{p}=$ 0.001; Fig. 2c) and more species $\left(\mathrm{B}_{\mathrm{F} n=11}=11, \mathrm{p}=\right.$ 0.001; Fig. 2d) of new settlers than those without. No new settlers were seen on flat corals, indicating either that larvae preferentially settle on fingered Montipora, or that they are quickly consumed upon settling on flat Montipora.

\section{Patterns of fish occurrence in Montipora}

Fish density differed among corals in different habitats, with Montipora in sand flats harboring $~ 10 \times$ more fish than those in continuous or patch reefs $\left(F_{2,254}=65.61, \mathrm{p}<0.0001\right.$; Fig. 3a). Species richness similarly differed among habitats, with Montipora in sand flats having greater species richness per area than continuous or patch reefs $\left(F_{2,254}=105.20, \mathrm{p}<\right.$ 0.0001; Fig. 3b).

Corals in sand flats were almost exclusively Montipora, which were larger and more distantly separated from other corals than Montipora in continuous or patch reefs. Both colony area $\left(F_{1,781.18}=7.8668, \mathrm{p}=\right.$ 0.0080 ) and distance from the nearest branching coral $\left(F_{1,454.21}=4.5741, \mathrm{p}=0.0391\right)$ had significant effects on reef fish abundance on colonies within sand flats. The number of fish inhabiting corals increased with increasing size $\left(F_{1,39}=18.17, \mathrm{p}<\right.$ $0.0001, R^{2}=0.32$; Fig. 4a) and increasing distance from other branching corals $\left(F_{1,39}=6.64, \mathrm{p}=0.0139\right.$, $\mathrm{R}^{2}=0.15$; Fig. 4b).

\section{Quality of coral structure as refuge}

The laboratory experiment demonstrated that bluegreen chromis survival differed among coral types $\left(F_{2,32.93}=48.59, \mathrm{p}<0.0001\right)$. Post hoc analysis revealed significant differences among all 3 coral types, with twice as many fish surviving on Pocillopora as on fingered Montipora, and about twice as many surviving on fingered Montipora as on flat
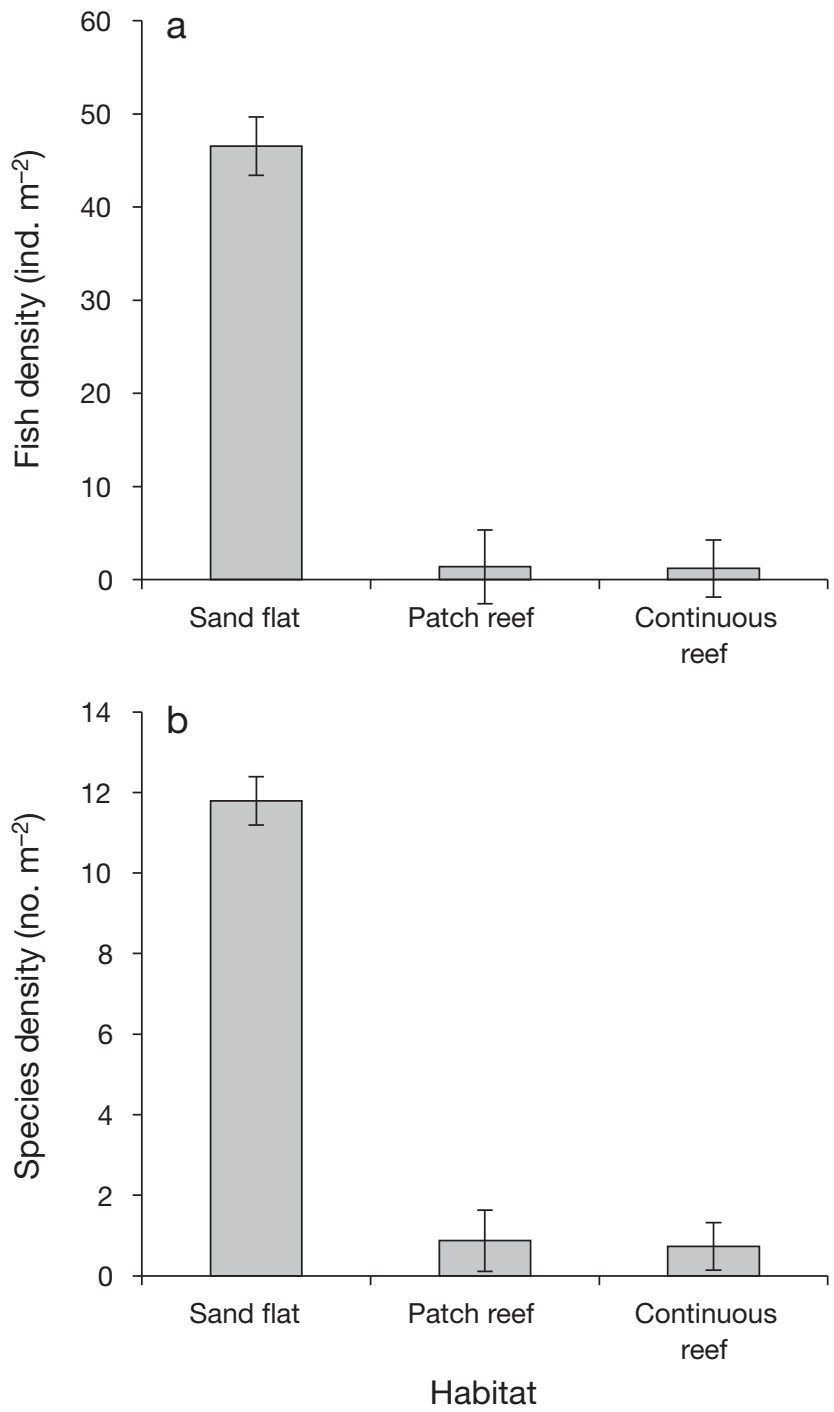

Fig. 3. (a) Number of individual fish per $\mathrm{m}^{2}$ of coral and (b) number of fish species per $\mathrm{m}^{2}$ of coral found on fingered Montipora colonies surveyed in continuous reef $(n=100)$, patch reef $(n=60)$, and sand flat $(n=97)$ habitats in the northern lagoons of Moorea. Means $\pm \mathrm{SE}$

Montipora (Fig. 5). Pocillopora therefore represents the highest-quality refuge among the 3 coral types tested, with fingered Montipora providing an intermediate level and flat Montipora providing the lowest quality refuge.

\section{Quantification of sand flats within the lagoon}

Image analysis revealed that sand flats compose $20.02 \pm 2.76 \%$ (mean $\pm \mathrm{SE}$ ) of the northern lagoon's area. Continuous and patch reef areas were generally located on the seaward half of the lagoon, 


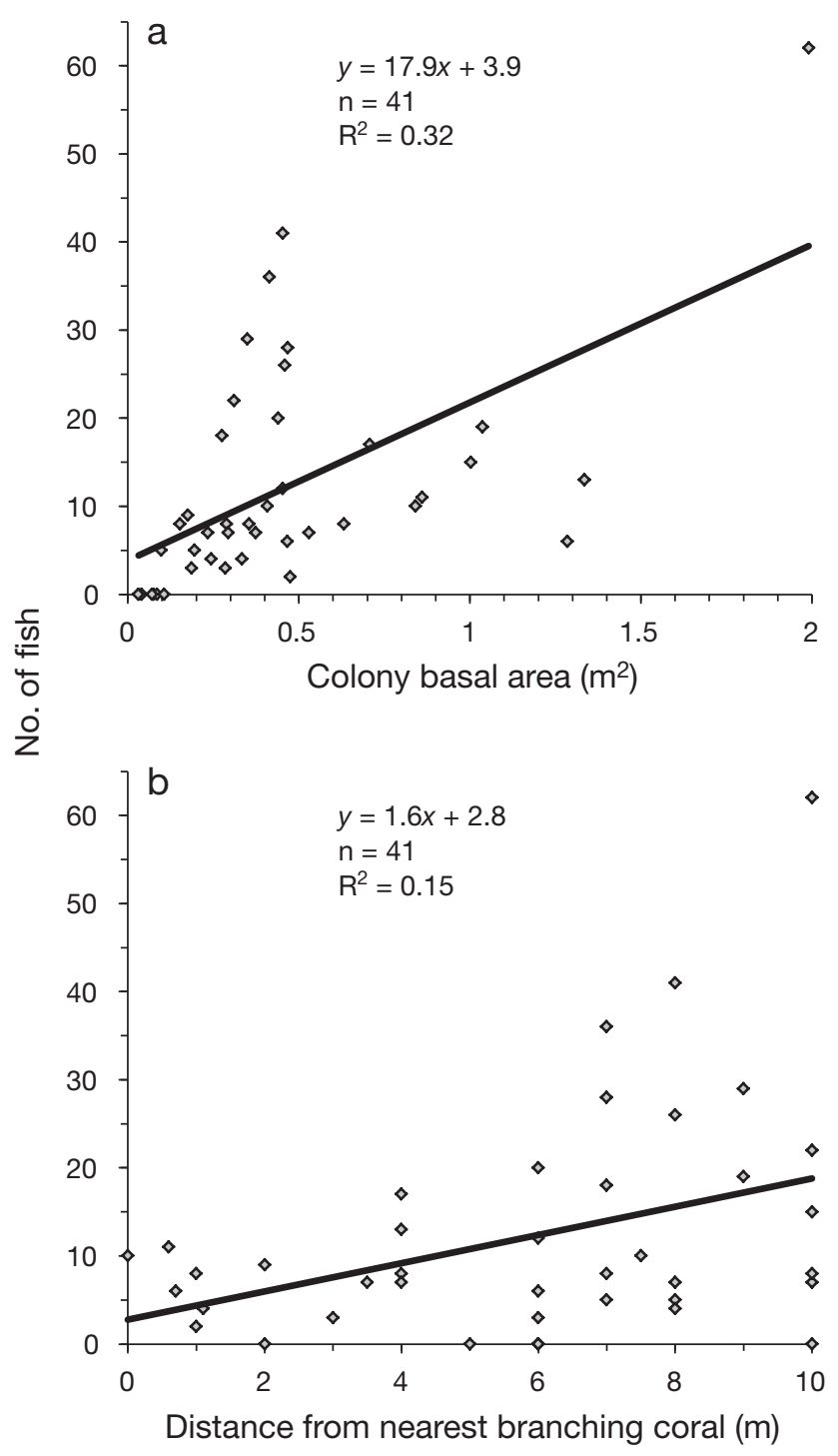

Fig. 4. Linear least-squares fit between the number of reef fish and (a) colony basal area and (b) distance from the nearest branching coral for fingered Montipora colonies found in sand flat habitats

whereas sand flats were generally shoreward of continuous and patch reefs and adjacent to deep-water channels (Fig. 6).

\section{DISCUSSION}

The results show that Montipora colonies with fingers harbor greater numbers and diversity of fish than those without (Fig. 2). This could be due to a number of factors, including the presence of the symbionts as prey, the increased structural complexity induced by the symbionts, or the greater surface area

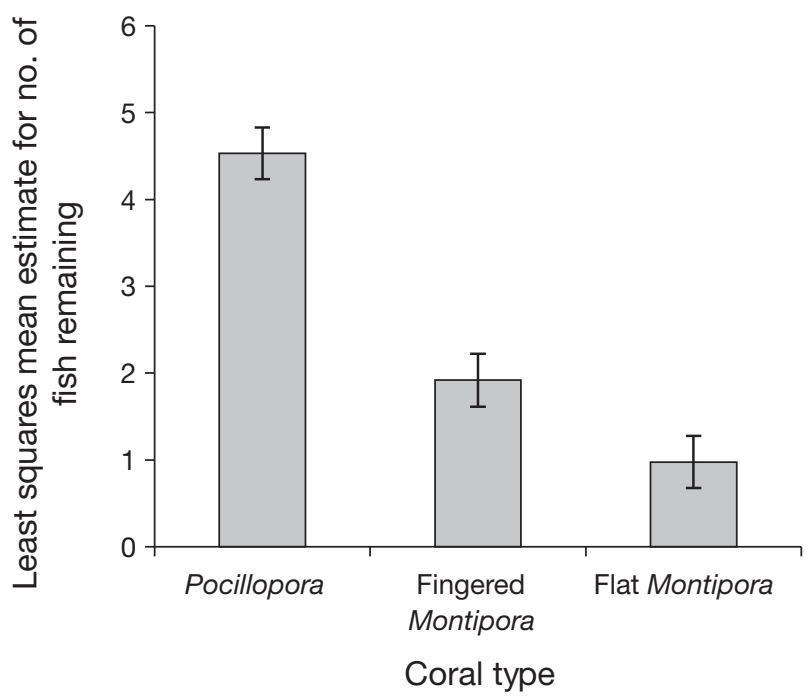

Fig. 5. Least-squares mean estimates $( \pm \mathrm{SE})$ from a mixed effect linear model for the number of juvenile fish remaining on 3 types of coral following exposure to a predator $(n=216)$

of living coral arising from the induced structure. While fish readily eat amphipods removed from their tubes in the laboratory, Bergsma \& Martinez (2011) found no evidence that fish eat symbionts within their tubes in the laboratory or in the field. Furthermore, the damselfish species that were most abundant on fingered Montipora are planktivores, and would not likely forage on embedded symbionts. This suggests that the patterns observed are not driven by differences in the availability of symbionts as a food source. Coral surface area is also unlikely to drive the observed patterns. Few of the observed fish were corallivores, and the surveys found numerous instances of fish inhabiting small fingered corals, but few instances of fish inhabiting large flat corals.

Fish abundance and diversity are therefore most likely responding to changes in the structural complexity of coral. This is consistent with numerous previous studies (e.g. Gladfelter \& Gladfelter 1978, Chabanet et al. 1997, Holbrook et al. 2002), and might arise through a number of mechanisms. For example, structures can act as physical barriers, attenuating currents and wave force (Kohn \& Leviten 1976). The fingered Montipora may attract fish because the fingers baffle flow, providing fish refuge from currents and preventing larvae from being swept away. Structural complexity also alters predator-prey dynamics (Huffaker 1958, Connell \& Jones 1991), and coral structure provides fish with important refuge from predation (Hixon \& Beets 1993, Holbrook \& Schmitt 2002). The laboratory experiment found that juvenile fish avoided predation better on Montipora with fin- 

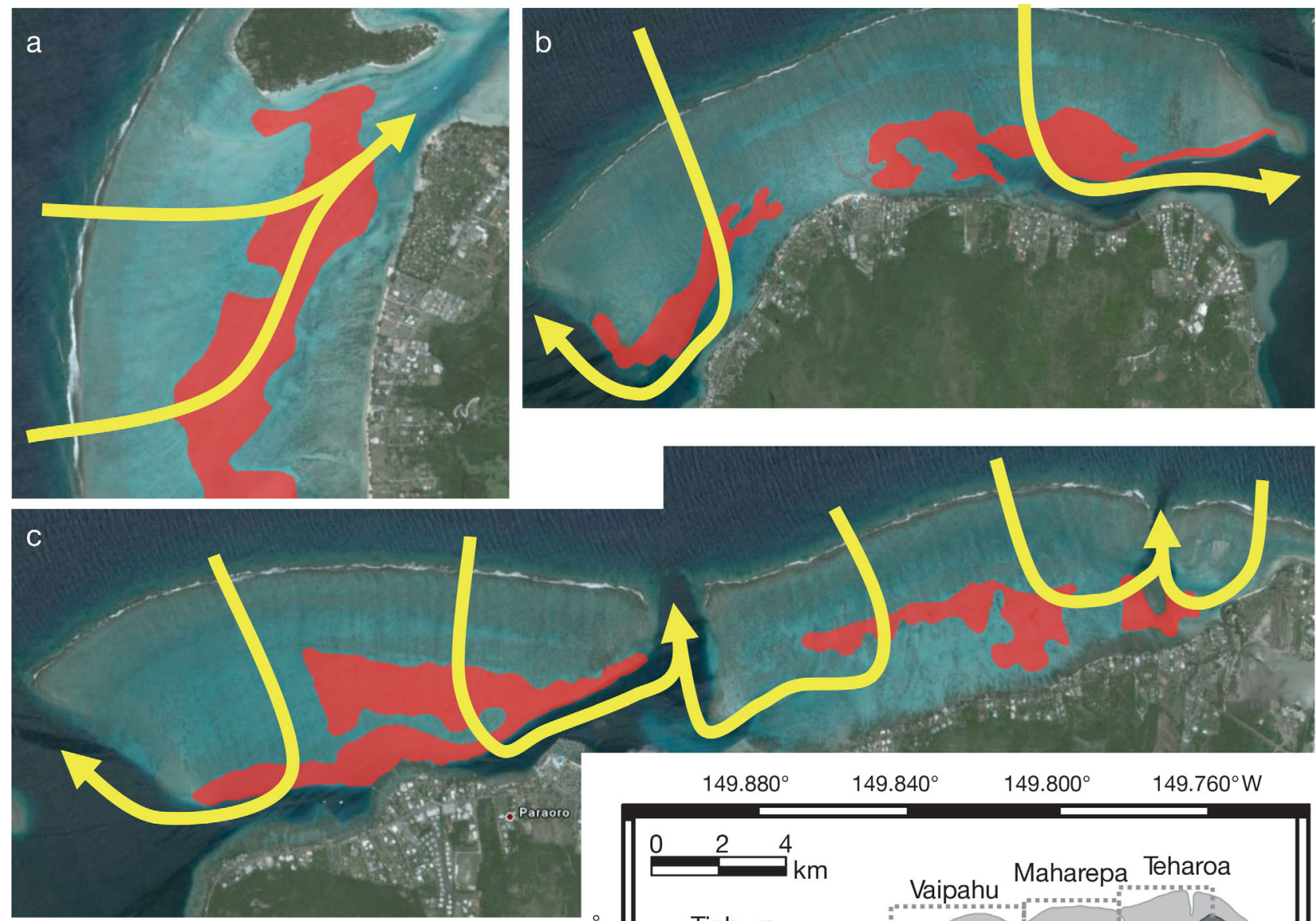

Satellite Images (C) 2007 DigitalGlobe, (C) 2007 Europa Technologies. (C) 2007 Google $^{\text {TM }}$

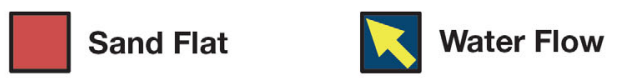

Fig. 6. Satellite images showing location of sand flats and direction of predominant current for the (a) Ahuru, (b) Vaipahu, and (c) Maharepa and Teharoa lagoons along the north shore of Moorea, French Polynesia (inset). Water flows (yellow arrows) into the lagoon over the reef crest, and is directed towards the reef passes inside the lagoon (Hench et al. 2008). Sand flats (red areas) are usually located on the shoreward end of lagoon reef flats, often adjacent to deep-water channels leading towards bays and reef passes

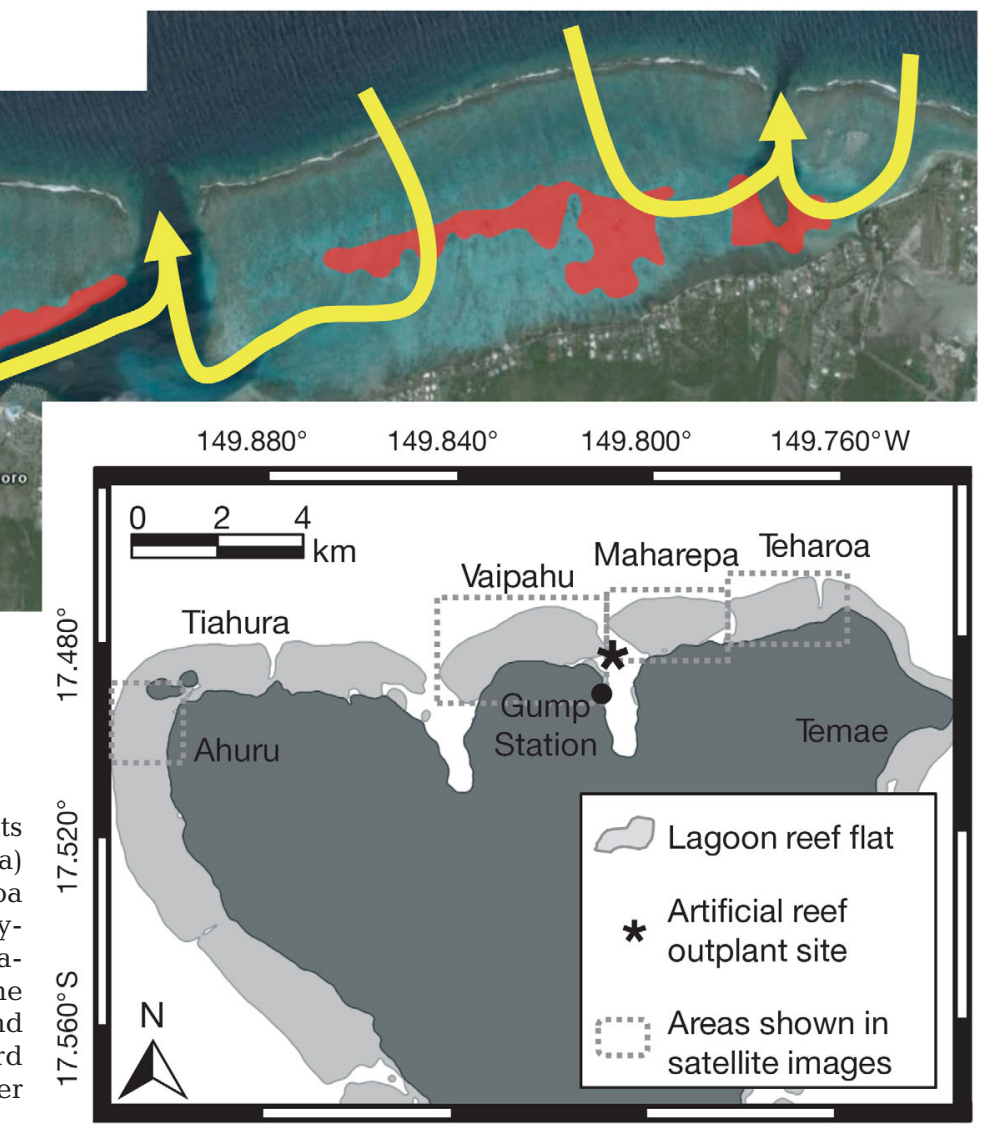

gers than Montipora without fingers (Fig. 5), indicating that fingers improve the habitat characteristics of Montipora and increase the amount of refuge space available to fish across the reef. This demonstrates that induced morphological changes in a foundation species can alter the diversity and abundance of organisms the species facilitates. The worms and amphipods are acting as allogenic ecosystem engineers by inducing morphological changes in a habitat-forming species, thereby altering benthic habitat for coral-associated organisms.
While the surveys found fish utilizing fingered Montipora across Moorea's lagoons, interestingly, only big, isolated colonies of fingered Montipora in sand flats harbored large numbers of fish (Figs. 3 \& 4). Pocillopora provided better refuge to fish than Montipora in the laboratory (Fig. 5), suggesting that Montipora may be lower-quality habitat than true branching corals. This could explain why fish do not utilize Montipora in continuous and patch reef habitats where branching corals are abundant. In sand flats, where Montipora is dominant, fish density 
increased with distance from the nearest branching coral (Fig. 4), indicating that fish might only inhabit Montipora when nothing better is readily available.

Despite the lower quality of Montipora as habitat, the fingered Montipora may augment lagoon fish populations due to the spatial arrangement of the sand flats and current patterns. Current flow across Moorea's lagoons is nearly unidirectional, with waves driving water over the reef crest and across the back reef towards the deep-water channels and bays before exiting the lagoon system through reef passes (Hench et al. 2008). Sand flats are commonly found on the shoreward side of the lagoons, often near deeper channels and bays (Fig. 6). Water velocities reported for the lagoon (Hench et al. 2008) are greater than the swimming speeds reported for latestage fish larvae (Stobutzki \& Bellwood 1997, Leis \& Carson-Ewart 2002), so larvae that are competent to settle are likely to be carried along by the current. Fish larvae being swept over the reef have passed over preferred habitats before they encounter sand flats and pass over sand flats just before they are carried into deep-water channels and bays (Fig. 6). Montipora in these sand flats could therefore be the last chance for larvae to settle on the reef flat. Additionally, the bays accumulate larvae (Leis et al. 2003) that can increase settlement to sandy areas at the deep water's periphery. Montipora in sand flats might therefore act as catchments, collecting fish settlers that would otherwise be lost from the system.

The sand flats also compose a large proportion of the lagoon's area, and the ability of Montipora to inhabit these areas substantially increases the amount of coral habitat across the reef flat. Fish recruitment and abundance in Moorea are limited by habitat availability (Holbrook et al. 2000, Schmitt \& Holbrook 2000). Additional habitat should therefore enhance reef fish recruitment and abundance, and the structures provided by the fingers in sand flats likely positively impact reef fish populations. Furthermore, the presence of competitively dominant fish on Pocillopora greatly suppresses successful settlement and early recruitment (Schmitt \& Holbrook 2000, Holbrook et al. 2011). Hence, even though fingered Montipora provides poorer refuge habitat than Pocillopora, fingered Montipora might be important settlement habitat if settlers are competitively excluded from their preferred habitat. Settlers may initially settle to Montipora and subsequently move to Pocillopora when they are stronger space competitors.

Ultimately, this study suggests that the presence of the epibiotic amphipods and worms serves to increase coral-associated fish abundance and diversity across the lagoons. Tube-building amphipods and worms are important ecosystem engineers in many temperate, soft-bottom communities (Bell 1985, Rabaut et al. 2007), but their role in creating habitat structure in coral has not been previously recognized. By augmenting settlement and refuge space, the epibiotic mutualists act as keystone facilitators, driving community structure through traitmediated indirect interactions. Because the mutualists facilitate coral growth and survival through induced morphological changes (Bergsma \& Martinez 2011) and the corals with altered morphology facilitate coral-associated reef fish, this is a unique example of a morphology-mediated facilitation cascade (Altieri et al. 2007, Thomsen et al. 2010). Trait-mediated facilitation likely occurs in many ecosystems; mycorrhizal-plant and plant root-root interactions, for example, demonstrate that positive interactions can induce morphological changes in terrestrial foundation species (Hetrick 1991, Hauggaard-Nielsen \& Jensen 2005, Bais et al. 2006). However, the indirect effects of these changes have not been previously explored, and may be more important in structuring communities than previously thought.

Acknowledgements. I thank J. Gowan, R. Pelc, H. Stewart, M. Kissinger, and K. Seydel for field assistance; A. Brooks and T. Adam for aid with fish identification; W. Rice for advice on statistical analyses; and S. Holbrook, R. Schmitt, G. Hofmann, C. Birkeland, and 3 anonymous reviewers for comments on the manuscript. This research was supported by the National Science Foundation (OCE 04-17412) and the Gordon and Betty Moore Foundation. This is a contribution of the Moorea Coral Reef Long Term Ecological Research site and the UC Berkeley Richard B. Gump South Pacific Research Station.

\section{LITERATURE CITED}

Abelson A, Galil BS, Loya Y (1991) Skeletal modifications in stony corals caused by indwelling crabs: hydrodynamical advantages for crab feeding. Symbiosis 10:233-248

- Altieri AH, Silliman BR, Bertness MD (2007) Hierarchical organization via a facilitation cascade in intertidal cordgrass bed communities. Am Nat 169:195-206

Bais HP, Weir TL, Perry LG, Gilroy S, Vivanco JM (2006) The role of root exudates in rhizosphere interactions with plants and other organisms. Annu Rev Plant Biol 57: 233-266

> Bell SS (1985) Habitat complexity of polychaete tube-caps: influence of architecture on dynamics of a meioepibenthic assemblage. J Mar Res 43:647-671

> Bergsma G (2009) Tube-dwelling coral symbionts induce significant morphological change in Montipora. Symbiosis 49:143-150 
Bergsma G, Martinez C (2011) Mutualist-induced morphological changes enhance growth and survival of corals. Mar Biol 158:2267-2277

Bertness MD, Callaway R (1994) Positive interactions in communities. Trends Ecol Evol 9:191-193

Bruno JF, Bertness MD (2001) Habitat modification and facilitation in benthic marine communities. In: Bertness MD, Gaines SD, Hay ME (eds) Marine community ecology. Sinauer Associates, Sunderland, MA, p 201-218

> Callaway RM, Pennings SC, Richards CL (2003) Phenotypic plasticity and interactions among plants. Ecology 84: 1115-1128

> Chabanet P, Ralambondrainy H, Amanieu M, Faure G, Galzin R (1997) Relationships between coral reef substrata and fish. Coral Reefs 16:93-102

Connell SD, Jones GP (1991) The influence of habitat complexity on postrecruitment processes in a temperate reef fish population. J Exp Mar Biol Ecol 151:271-294

Galzin R, Pointier JP (1985) Moorea Island, Society Archipelago. In: Delesalle B, Galzin R, Salvat B (eds) Proc 5th Int Coral Reef Congr, Tahiti 1:73-102

Gladfelter WB, Gladfelter EH (1978) Fish community structure as a function of habitat structure on West Indian patch reefs. Rev Biol Trop 26:65-84

Gribben PE, Byers JE, Clements M, McKenzie LA, Steinberg PD, Wright JT (2009) Behavioural interactions between ecosystem engineers control community species richness. Ecol Lett 12:1127-1136

Hauggaard-Nielsen H, Jensen ES (2005) Facilitative root interactions in intercrops. Plant Soil 274:237-250

> Hench JL, Leichter JJ, Monosmith SG (2008) Episodic circulation and exchange in a wave-driven coral reef and lagoon system. Limnol Oceanogr 53:2681-2694

Hetrick BAD (1991) Mycorrhizas and root architecture. Experientia 47:355-362

- Hixon MA, Beets J (1993) Predation, prey refuges, and the structure of coral reef fish assemblages. Ecol Monogr 63: 77-101

Holbrook SJ, Schmitt RJ (2002) Competition for shelter space causes density-dependent predation mortality in damselfishes. Ecology 83:2855-2868

> Holbrook SJ, Forrester GE, Schmitt RJ (2000) Spatial patterns in abundance of a damselfish reflect availability of suitable habitat. Oecologia 122:109-120

- Holbrook SJ, Brooks AJ, Schmitt RJ (2002) Variation in structural attributes of patch-forming corals and in patterns of abundance of associated fishes. Mar Freshw Res 53:1045-1053

Holbrook SJ, Schmitt RJ, Brooks AJ (2008) Resistance and resilience of a coral reef fish community to changes in coral cover. Mar Ecol Prog Ser 371:263-271

Holbrook SJ, Schmitt RJ, Brooks AJ (2011) Indirect effects of species interactions on habitat provisioning. Oecologia 166:739-749

Huffaker CK (1958) Experimental studies on predation: dispersion factors and predator-prey oscillations. Hilgardia 27:343-383

> Irving AD, Bertness MD (2009) Trait-dependent modification of facilitation on cobble beaches. Ecology 90: 3042-3050

> Jones CG, Lawton JH, Shachak M (1994) Organisms as ecosystem engineers. Oikos 69:373-386
Jones CG, Lawton JH, Shachak M (1997) Positive and negative effects of organisms as physical ecosystem engineers. Ecology 78:1946-1957

Kohn AJ (1983) Microhabitat factors affecting abundance and diversity of Conus on coral reefs. Oecologia 60: 293-301

> Kohn AJ, Leviten PJ (1976) Effect of habitat complexity on population density and species richness in tropical intertidal predatory gastropod assemblages. Oecologia 25: 199-210

Leis JM, Carson-Ewart BM (2002) In situ settlement behaviour of damselfish (Pomacentridae) larvae. J Fish Biol 61: 325-346

Leis JM, Trnski T, Dufour V, Harmelin-Vivien M, Renon JP, Galzin R (2003) Local completion of the pelagic larval stage of coastal fishes in coral-reef lagoons of the Society and Tuamotu Islands. Coral Reefs 22:271-290

Liu PJ, Hsieh HL (2000) Burrow architecture of the spionid polychaete Polydora villosa in the corals Montipora and Porites. Zool Stud 39:47-54

Menge B (1995) Indirect effects in marine rocky intertidal interaction webs: patterns and importance. Ecol Monogr 65:21-74

Nakamura Y, Shibuno T, Lecchini D, Kawamura T, Watanabe Y (2009) Spatial variability in habitat associations of pre- and post-settlement stages of coral reef fishes at Ishigaki Island, Japan. Mar Biol 156:2413-2419

> Ohman MC, Munday PL, Jones GP, Caley MJ (1998) Settlement strategies and distribution patterns of coral reef fishes. J Exp Mar Biol Ecol 225:219-238

Rabaut M, Guilini K, Van Hoey G, Vincx M, Degraer S (2007) A bio-engineered soft-bottom environment: the impact of Lanice conchilega on the benthic species-specific densities and community structure. Estuar Coast Shelf Sci 75:525-536

Rasband WS (2005) ImageJ. US National Institutes of Health, Bethesda, MD

> Schmitt RJ, Holbrook SJ (2000) Habitat-limited recruitment of coral reef damselfish. Ecology 81:3479-3494

> Stachowicz JJ (2001) Mutualism, facilitation, and the structure of ecological communities. Bioscience 51:235-246

Stobutzki IC, Bellwood DR (1997) Sustained swimming abilities of the late pelagic stages of coral reef fishes. Mar Ecol Prog Ser 149:35-41

Thomsen MS, Wernberg T, Altieri A, Tuya F and others (2010) Habitat cascades: the conceptual context and global relevance of facilitation cascades via habitat formation and modification. Integr Comp Biol 50: 158-175

Todd PA (2008) Morphological plasticity in scleractinian corals. Biol Rev Camb Philos Soc 83:315-337

Vytopil E, Willis BL (2001) Epifaunal community structure in Acropora spp. (Scleractinia) on the Great Barrier Reef: implications of coral morphology and habitat complexity. Coral Reefs 20:281-288

Wielgus J, Glassom D, Ben-Shaprut O, Chadwick-Furman NE (2002) An aberrant growth form of Red Sea corals caused by polychaete infestations. Coral Reefs 21: 315-316

- Wootton JT (1994) The nature and consequences of indirect effects in ecological communities. Annu Rev Ecol Syst 25:443-466 
Appendix 1. Fish taxa that used Montipora fingers as habitat

\begin{tabular}{|c|c|c|}
\hline Family & Species & Common name \\
\hline Acanthuridae & Acanthurus nigrofuscus & Brown surgeonfish \\
\hline Acanthuridae & Acanthurus triostegus & Convict tang \\
\hline Acanthuridae & Ctenochaetus striatus & Striped bristletooth \\
\hline Acanthuridae & Zebrasoma scopas & Brushtail tang \\
\hline Antennariidae & Antennarius & Frogfish \\
\hline Apogonidae & Apogon fraenatus & Bridled cardinalfish \\
\hline Apogonidae & Cheilodipterus quinquelineatus & Fivelined cardinalfish \\
\hline Balistidae & Balistapus undulatus & Orange-lined triggerfish \\
\hline Chaetodontidae & Chaetodon citrinellus & Speckled butterflyfish \\
\hline Chaetodontidae & Chaetodon lunulatus & Oval (redfin) butterflyfish \\
\hline Chaetodontidae & Chaetodon unimaculatus & Teardrop butterflyfish \\
\hline Cirrhitidae & Paracirrhites arcatus & Arc-eye hawkfish \\
\hline Gobiidae & & Gobies \\
\hline Holocentridae & Neoniphon sammara & Spotfin squirrelfish \\
\hline Holocentridae & Sargocentron melanospilos & Finelined squirrelfish \\
\hline Labridae & Cheilinus chlorourus & Floral wrasse \\
\hline Labridae & Halichoeres trimaculatus & Threespot wrasse \\
\hline Labridae & Pseudocheilinus hexataenia & Sixline wrasse \\
\hline Labridae & Thalassoma amblycephalum & Blunt-head wrasse \\
\hline Labridae & Thalassoma hardwicke & Sixbar wrasse \\
\hline Lethrinidae & Monotaxis grandoculis & Bigeye bream \\
\hline Mullidae & Mulloidichthys flavolineatus & Yellowstripe goatfish \\
\hline Muraenidae & Echidna nebulosa & Snowflake moray \\
\hline Ostraciidae & Ostracion meleagris & Spotted trunkfish \\
\hline Pomacanthidae & Centropyge flavissima & Lemonpeel angel \\
\hline Pomacentridae & Chromis iomelas & Half \& half chromis \\
\hline Pomacentridae & Chromis margaritifer & Bicolor chromis \\
\hline Pomacentridae & Chromis viridis & Bluegreen chromis \\
\hline Pomacentridae & Dascyllus aruanus & Humbug dascyllus \\
\hline Pomacentridae & Dascyllus flavicaudus & Yellowtail dascyllus \\
\hline Pomacentridae & Dascyllus trimaculatus & Threespot dascyllus \\
\hline Pomacentridae & Pomacentrus pavo & Sapphire damsel \\
\hline Pomacentridae & Stegastes nigricans & Dusky gregory \\
\hline Scorpaenidae & & Scorpionfish \\
\hline Serranidae & Cephalopholis argus & Peacock grouper \\
\hline Serranidae & Epinephelus merra & Honeycomb grouper \\
\hline Tetradontidae & Canthigaster solandri & Speckled toby \\
\hline
\end{tabular}

Editorial responsibility: Charles Birkeland, Honolulu, Hawaii, USA
Submitted: August 22, 2011; Accepted: January 1, 2012 Proofs received from author(s): April 3, 2012 